\title{
STRATEGI SOFT POWER DALAM EKSPANSI EKONOMI CHINA DI TIMUR TENGAH: STUDI KASUS KERJASAMA CHINA-IRAN
}

\author{
Dina Yulianti \\ Dosen Hubungan Internasional, Universitas Padjadjaran, Bandung \\ Email: dina14@unpad.ac.id \\ R. Muhammad Teguh Nurhasan Affandi \\ Dosen Hubungan Internasional, Universitas Padjadjaran, Bandung \\ Email: rmthiunpad@gmail.com
}

\begin{abstract}
Abstrak
Mundurnya AS secara sepihak dari JCPOA pada bulan Mei 2018 dan upaya AS kembali mengembargo Iran, menurut sejumlah pengamat, telah memberikan peluang bagi China untuk memperbesar dominasi ekonominya di Timur Tengah. Sebelumnya pum, China telah secara aktif menjalin hubungan ekonomi dengan nilai yang sangat signifikan dengan negara-negara Timur Tengah. Fenomena ini memunculkan pertanyaan penelitian, apakah kunci keberhasilan China dalam melakukan ekspansi ekonomi di Timur Tengah di tengah berbagai konflik yang ada di kawasan itu? Penulis akan memfokuskan penelitian terhadap strategi soft power China yang diasumsikan memiliki peran besar dalam keberhasilan kerjasama ekonomi dan perdagangan negara tersebut di kawasan, terutama dalam kasus kerjasama ChinaIran. Melalui penelahaan literatur, dokumen, dan berita media massa, kajian ini menemukan dimensi baru dalam strategi soft power China di Iran, yaitu sangat kuatnya peran 'nilai', antara lain nilai kesetiaan, perlawanan terhadap radikalisme dan terorisme, dan resistensi terhadap dominasi AS.
\end{abstract}

Kata kunci: China, Timur Tengah, Iran, soft power, nilai

\begin{abstract}
The unilateral United States withdrawal from JCPOA in May 2018 and US efforts to embargo Iran, according to some observers, have provided opportunities for China to enlarge its economic dominance in the Middle East. Previously, China have actively established strong economic relations with most of Middle Eastern countries. This phenomenon raises research questions, what is the key to China's success in carrying out economic expansion in the Middle East in the midst of various conflicts in the region? The authors focuses the research on China's soft power strategy which is assumed to have a big role in the success of the country's economic and trade cooperation in the region, especially in the case of China-Iran cooperation. Through reviewing literature and mass media news, this study found a new dimension in China's soft power strategy towards Iran, namely the very strong role of 'value', including the value of loyalty, refusal towards radicalism and terrorism, and resistance to US domination.
\end{abstract}

Keywords: China, Iran, Middle East, soft power, values 


\section{Pendahuluan}

Keluarnya AS dari Joint Comprehensive Plan of Action (JCPOA) pada bulan Mei 2018 dan disertai dengan pemberian sanksi ekonomi kepada Iran, memunculkan reaksi beragam dari negara-negara yang memiliki hubungan bisnis dengan Iran. Dua di antara importir utama minyak Iran, India dan Korea Selatan, telah menghentikan impor mereka karena ancaman sanksi itu itu diberikan AS kepada negara-negara yang tetap melakukan pembelian minyak Iran. Sementara itu, importir minyak terbesar Iran, China, telah menyatakan tidak akan menghentikan kerjasamanya dengan Iran dan bahkan akan meningkatkan volume impor minyaknya (Donati, 2018).

Menurut Menteri Luar Negeri China, kerjasama bisnis antara China dan Iran tidak menganggu kepentingan pihak lain sehingga seharusnya dikecualikan dari sanksi AS. Lebih jauh ia menambahkan, "Ikatan komersial antara China dan Iran sepenuhnya masuk akal dan sejalan dengan resolusi PBB" (Sputnik, 2018).

$$
\text { Pengamat ekonomi }
$$
memprediksi, China adalah negara yang paling diuntungkan dari mundurnya AS dari JCPOA. Bila Uni Eropa menuruti kehendak AS untuk mengembargo Iran, perusahaan China akan mengisi kekosongan yang ditinggalkan oleh perusahaanperusahaan Eropa. Menurut The National Iranian Oil Company (NIOC), China National Petroleum Corporation mungkin akan mengambil alih saham senilai 5 miliar USD dari perusahaan Perancis dalam pembangunan ladang gas raksasa Iran, South Pars Gas Field. China merupakan partner dagang terbesar Iran, yaitu sekitar $22,3 \%$ dari nilai total perdagangan Iran. Proyek One Belt One Road (OBOR) yang diinisiasi China juga semakin memperluas kerjasama ekonomi dan perdagangan di antara keduanya (Financial Tribune, 2018).

Kerjasama ekonomi yang erat juga dilakukan China dengan negaranegara Timur Tengah lainnya. Sejak 2010, China telah menggantikan AS sebagai partner perdagangan terkuat di kawasan dan kerjasama ekonomi itu semakin diperkuat pada tahun-tahun berikutnya. Pada 10 Juli 2017, China mengundang 22 negara anggota Liga Arab ke Beijing dalam pertemuan para 
menteri China dan negara-negara Arab (The 8th Ministerial Meeting of the China-Arab States Cooperation Forum - CASCF). Dalam pertemuan ini China menjanjikan pinjaman sebesar 20 miliar USD yang akan digunakan untuk proyek-proyek infrastruktur, bantuan kemanusiaan dan rekonstruksi di kawasan terdampak perang (Suriah, Yaman, Yordania, dan Lebanon) sebesar 90,6 juta USD, serta pinjaman khusus untuk pengembangan sektor finansial (Zhou, 2018).

\section{Hal yang menarik dari} fenomena ini adalah bahwa China mampu menjalin kerjasama dengan negara-negara Timur Tengah yang satu sama lain saling berseteru. Ketika di saat yang sama China seolah menjadi 'pelindung' bagi Iran di tengah embargo yang dilancarkan AS, China merupakan partner yang serius bagi Arab Saudi yang merupakan rival Iran di kawasan. Pada Maret 2017, Raja Arab Saudi, Salman bin Abdulaziz berkunjung ke Beijing dan kedua pihak menandatangani MoU kerjasama ekonomi, terutama di bidang investasi minyak dan energi terbarukan, yang nilainya mencapai 65 miliar USD. Kerjasama keamanan di antara kedua negara juga semakin meningkat, antara lain terlihat dari penggunaan drone (unmanned attack drones) buatan China dan dilaksanakannya latihan militer bersama anti-terorisme, serta semakin intensifnya manuver China di Teluk Aden (USA Today, 2017).

China bahkan menjadi mediator di tengah perseteruan Qatar dan Arab Saudi, yaitu dengan mempertemukan kedua pihak dalam forum CASCF di Beijing. Di saat yang sama, China menjadi salah satu pilar penyangga bagi Qatar dalam menghadapi embargo ekonomi yang dilakukan Arab Saudi dan sekutunya. Pasca embargo, ekspor China ke Qatar melonjak 36\% dan sebaliknya, ekspor Qatar ke China meningkat 60\%. China kini menggantikan AS sebagai sumber impor yang dilakukan Qatar (Chowdhury, 2018).

Meskipun keputusan China dalam berbagai Sidang Dewan Keamanan PBB sering bertentangan dengan kehendak Israel terkait isu nuklir Iran, kerjasama kedua negara menunjukkan peningkatan secara signifikan dalam beberapa tahun terakhir. Nilai perdagangan di antara keduanya melebihi 11 miliar USD atau sekitar 200 kali lipat 
dibandingkan 25 tahun sebelumnya (Abrams, 2018).

Ini menunjukkan kemampuan unik China untuk bernegosiasi dengan semua negara Timur Tengah yang beberapa di antaranya saling berseteru. China mampu melakukan kerjasama yang sifatnya strategis dan jangka panjang, tidak hanya di bidang ekonomi, melainkan juga keamanan dan diplomatik. Dalam isu nuklir Iran dan Perang Suriah, China menjadi aktor kuat yang berperan dalam mengubah tatanan geopolitik yang semula didominasi oleh AS dan Eropa. China terlihat mampu melakukan ekspansi ekonomi yang masif di Timur Tengah dengan cara berteman dengan semua negara di kawasan meskipun di antara mereka memiliki perbedaan kepentingan geopolitik yang amat tajam.

Fenomena ini melahirkan pertanyaan penelitian, apakah kunci keberhasilan China dalam melakukan ekspansi ekonomi di Timur Tengah?

$$
\text { Penelitian terdahulu }
$$

menyebutkan bahwa China sejak tahun 2007 telah menggunakan strategi soft power untuk mencapai kepentingan nasionalnya di berbagai kawasan. Dengan soft power China berupaya mempertahankan citranya sebagai kekuatan besar di kawasan yang tetap netral dan melakukan campur tangan terbatas (limitedinterference) dalam urusan politik dan keamanan (Osman, 2017). Soft power berperan penting dalam upaya China mempererat hubungan dengan negaranegara Timur Tengah demi menjamin sumber-sumber energi (McGiffert, 2009). Melalui soft power, China berupaya menggemakan prinsip utama kebijakan China, yaitu 'kebangkitan yang damai', untuk membantah narasi Barat yang mencitrakan China sebagai ancaman bagi tatanan internasional (Albert, 2018).

Dalam artikel ini, penulis akan meneliti strategi soft power China di Timur Tengah, dengan studi kasus kerjasama China-Iran. Iran diambil sebagai studi kasus karena isu nuklir Iran pasca JCPOA merupakan isu yang signifikan dan aktual di kawasan. Dari kajian ini diharapkan akan ditemukan dimensi baru dalam strategi soft power China, terlebih karena Iran memiliki karakteristik yang khas, yaitu sikap resisten yang sangat kuat atas terhadap tekanan global yang sudah berlangsung sejak tahun 1980an.

Penelitian dilakukan dengan analisis mendalam terhadap literatur, 
kajian terdahulu, dokumen, dan sumber-sumber media massa. Hasil penelitian dipaparkan dalam lima bagian, yaitu pendahuluan, kajian teoritis mengenai soft power, implementasi soft power China di Timur Tengah, analisis terhadap strategi soft power yang dilakukan China terhadap Iran, dan kesimpulan.

\section{Konsep Soft Power dan Implementasi Soft Power Gaya China}

Tulisan-tulisan Josep S. Nye Jr. merupakan rujukan utama dalam mendiskusikan konsep soft power. Nye mengembangkan konsep ini pertama kali pada tahun 1990 melalui bukunya Bound to Lead yang menjelaskan bahwa AS menjadi negara terkuat di dunia bukan karena kekuatan ekonomi dan militer yang dimilikinya, melainkan juga berkat soft power. Di buku keduanya, The Paradox of American Power (2002), Nye memperingatkan AS bahwa mempertahankan kebijakan hard power (militerisme) dan mengabaikan soft power akan menempatkan AS dalam posisi yang rentan; apalagi di era globalisasi yang memberi kesempatan kepada kekuatan-kekuatan lain (di antaranya China) untuk penjadi pesaing bagi AS.

Di buku ketiganya yang berjudul Soft Power: The Means To Success in World Politics (2004), Nye mengkritisi militerisme AS (invasi ke Irak) yang meskipun meraih kemenangan, telah membuat berkurang drastisnya dukungan dunia terhadap AS. Menurut Nye, "Winning the peace is harder than winning a war, and soft power is essential to winning the peace."

Nye mengumpamakan power dengan cuaca; semua orang membicarakannya tetapi sedikit yang mampu memahami. Dia juga menganalogikan power dengan cinta; mudah dirasakan tetapi sulit untuk mendefinisikan dan mengukurnya. Namun secara khusus, power adalah kemampuan untuk mempengaruhi pihak lain untuk mendapatkan hal-hal yang diinginkan. Menurut Nye, ada beberapa cara untuk mempengaruhi perilaku orang lain, baik itu menggunakan hard power (berupa ancaman atau uang; sticks and carrots), atau mengupayakan agar pihak lain memiliki ketertarikan (attraction). Soft power adalah kemampuan untuk mendapatkan halhal yang diinginkan sebuah negara 
dengan mengupayakan pihak lain tertarik pada budaya, ide politik, dan kebijakan negara tersebut (Nye, 2004: $\mathrm{x}, 1-2)$

Nye menjelaskan bahwa soft power tidak benar-benar sama dengan 'pengaruh' (influence) karena sebuah negara juga dapat mempengaruhi negara lain dengan menggunakan hard power (baik ancaman atau uang). Soft power adalah kemampuan sebuah negara untuk menarik (to attract) dengan melalui langkah-langkah agenda setting, lalu membuat pihak lain tertarik, dan akhirnya pihak lain melakukan apa yang diinginkannya. Ketika sebuah negara mampu membuat pihak lain melakukan apa yang dikehendakinya melalui paksaan maupun uang (hard power), negara itu tengah menggunakan command power-nya. Command power merupakan bagian dari hard power. Sebaliknya, bila negara itu mampu membentuk keinginan negara lain agar sejalan dengan keinginanya, tanpa paksaan atau bujukan (dengan uang), negara tersebut dipandang memiliki co-optive power, yang merupakan bagian dari soft power. Sumber daya yang dibutuhkan untuk mencapai $c o$ optive power adalah institusi, nilai, budaya, dan kebijakan.
Hubungan antara konsepkonsep ini dapat disarikan dalam bagan berikut ini.

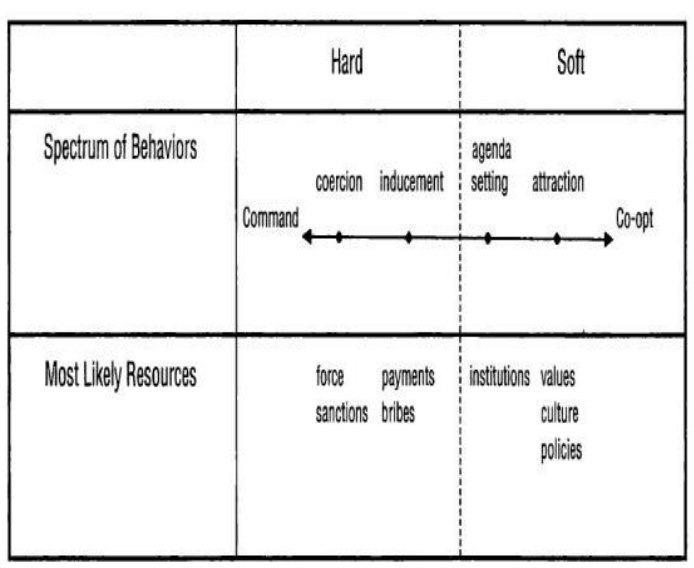

Sumber: Nye (2004:8)

Ketika sebuah negara (misalnya, negara A) mampu membentuk aturan internasional (dalam bentuk institusi) yang sejalan dengan kepentingan dan nilai-nilainya; dan menggunakan institusi ini untuk mengatur negara lain (misalnya, negara B) agar bertindak sesuai kepentingannya, artinya negara A telah menggunakan soft power-nya melalui institusi (Nye, 2004:9-10). Ketika budaya negara A mengandung nilai-nilai universal dan kebijakan negara A dalam mempromosikan nilai-nilai dan kepentingannya sejalan dengan nilai dan kepentingan negara B, kesempatan negara A dalam mendorong B melakukan apa yang diinginkannya akan lebih besar (Nye, 2004:11). 
Lebih lanjut Nye menjelaskan bahwa sumber dari sebagian besar soft power adalah masyarakat sipil. Misalnya, industri film Hollywood, institusi pendidikan AS, Microsoft, Google berperan penting dalam mempengaruhi budaya populer masyarakat dunia. Menurut Nye, era informasi meniscayakan semakin besarnya kekuatan soft power di tangan masyarakat sipil (Nye, 2004:17).

Konsep soft power diterima luas oleh kalangan akademisi China, terutama sejak tahun 2000. Di antara tahun 2000-2004, ada 53 artikel jurnal per tahun yang ditulis akademisi China berkenaan dengan soft power; dan meningkat menjadi 314 artikel per tahun pada 2005-2007 (Lai, 2012 dalam Osman, 2017:6). Pemerintah China juga melakukan berbagai kajian terkait konsep ini dan menyadari bahwa kemajuan ekonomi yang amat pesat dicapainya telah membuat dunia khawatir dan curiga sehingga China harus berupaya memberikan opini tandingan yang memberikan jaminan kepada dunia bahwa kebangkitan China adalah kebangkitan yang damai Pada tahun 2007, dalam Kongres Nasional Partai Komunis, pemerintah China mengumumkan akan menggunakan soft power sebagai strategi kebijakan luar negerinya. Hal ini sejalan dengan yang dikatakan E.H. Carr sejak 1939, bahwa international power terbagi tiga kategori yaitu militer, ekonomi, dan power over opinion (dalam Nye, 2004:8). Soft power merupakan kekuatan strategis untuk memenangkan opini publik di berbagai negara agar mereka menyambut positif kerjasama dengan China.

China mengembangkan konsep soft power Nye dengan memberikan penekanan pada penggunaan sumber daya institusi dan nilai. Mereka merumuskan enam elemen yang menjadi sumber bagi soft power China, yaitu kesuksesan ekonomi dan pembangunan ala China, perjanjianperjanjian Beijing dengan berbagai negara, relasi diplomatik yang canggih, perilaku yang terhormat di fora internasional, persatuan nasional, dan kemajuan sains-teknologi (Osman, 2017).

Implementasi Soft Power China di Timur Tengah

Saat berpidato di forum Liga Arab di Kairo, 21 Januari 2016, Presiden Xi Jinping terlihat memulai 
paparannya dengan mengenalkan nilai utama yang dianut China, yaitu kepercayaan (trust). Ia mengutip kalimat filsuf China, "Kunjungi orang yang kaurasa dekat denganmu meski belum pernah berjumpa dengannya; dan undanglah orang yang tak bisa kaulupakan meskipun telah lama tak berjumpa." $\mathrm{Xi}$ mengingatkan para pemimpin Dunia Arab bahwa bangsa China dan Arab telah menjalin persahabatan sejak zaman Jalur Sutra kuno, 'berbagi sedih dan lara dalam perjuangan kemerdekaan nasional' serta 'saling membantu dalam membangun negara masing-masing'. Menurut Xi, "Kepercayaan seperti itu tidak dapat dipisahkan dan tidak dapat dibeli dengan uang" (China Daily, 2016).

Hubungan China dengan negara-negara Arab pernah mengalami penurunan pada era Perang Dingin karena saat itu negara-negara Arab lebih memilih bersekutu dengan Barat dan memandang curiga pada ideologi komunisme yang dianut China yang dianggap sebagai sebuah keyakinan atheis. Dalam perseteruan ChinaTaiwan, sebagian besar negara Teluk mendukung Taiwan. Dalam voting di PBB tahun 1960-an, Arab Saudi mendukung Taiwan untuk mempertahankan kursi tetapnya di Dewan Keamanan. Negara-negara Arab juga memiliki pandangan negatif terhadap China yang memberikan pengakuan terhadap Israel. Dalam voting tahun 1951 untuk mengutuk China sebagai agresor dalam Perang Korea, Arab Saudi dan Yaman memilih abstain. Pada tahun 1971, China secara resmi duduk di PBB (menggantikan Taiwan) dan hubungan negara tersebut dengan negara-negara Arab terlihat membaik. Mulai 19711989, China menjadi penyuplai senjata penting di kawasan (Mikhail, 2017).

Pasca Perang Dingin, China mulai mengubah kebijakan luar negerinya dengan menunjukkan keaktifan dalam berbagai upaya perdamaian dunia serta menjalin kerjasama ekonomi secara luas. Perubahan ini terutama didorong oleh kekhawatiran bahwa bila China tidak mengejar ketertinggalan di bidang ekonomi, akan muncul ketidakpercayaan publik atas ideologi 'sosialisme dengan karakteristik China' sehingga berujung pada ketidakstabilan politik (Chen, 1993:241). China kemudian melakukan berbagai upaya untuk menghilangkan persepsi yang muncul di komunitas internasional bahwa 
China adalah ancaman, antara lain menandatangani Perjanjian Proliferasi Nuklir (1993) dan membuat komitmen untuk mematuhi Missile Technology Control Regimes; aktif mengikuti pertemuan Dewan Keamanan PBB untuk mendiskusikan pengontrolan senjata di Timur Tengah; melakukan upaya diplomatik ke Israel agar negara tersebut memberikan konsesi kepada negara-negara Arab sebagai bagian dari proses perdamaian dan memberikan jaminan bahwa China tidak akan menganggu jalannya proses perdamaian tersebut (Chen, 1993:244).

Presiden Xi dalam pidatonya di Liga Arab (2016) selain mengemukakan tawaran kerjasama ekonomi juga memaparkan adanya kerjasama pendidikan dan kebudayaan. Menurutnya, "Kami telah melakukan berbagai kegiatan dalam kerangka 'Tahun Persahabatan ChinaArab', menandatangani perjanjian pendirian 'universitas bersama' (joint university), dan memulai kerjasama antara 100 lembaga budaya dari kedua belah pihak" (China Daily, 2016).

Saat ini, ada sekitar 13 Confusius Institute di Timur Tengah yang bergerak mempromosikan bahasa dan budaya China dan memfasilitasi pertukaran budara. Kerjasama di bidang pendidikan dan budaya ini menunjukkan upaya menarik perhatian (attraction) bangsabangsa Arab terhadap China. Menurut Mohammad Fayez, Ketua Departemen Studi China di Al Ahram Strategic Studies Centre, pemerintah China memberikan perhatian besar pada pengajaran bahasa China di Dunia Arab dengan tujuan menumbuhkan generasi Arab yang memahami China dan menghargai spirit bahasa China sehingga kelak mereka membangun jembatan antara China dengan Dunia Arab. Selain mendirikan pusat pengajaran bahasa dan budaya, pemerintah China juga aktif mengadakan konferensi di berbagai kota di China dengan mengundang para akademisi Arab (Al Tamimi, 2017).

$$
\text { Dalam bidang }
$$

ekonomi, China menawarkan kerjasama ekonomi yang menguntungkan kedua pihak. Sebagaimana disampaikan Xi Jinping dalam pidatonya, China adalah partner dagang terbesar kedua bagi negaranegara Arab. Kedua pihak telah menjalin perjanjian perdagangan bebas (Free Trade Agreement), dua 'RMB clearing center' (pusat 
penyelesaian transaksi dengan mata uang RMB di bank tertentu), dan dua dana investasi gabungan (joint investement funds). China juga menawarkan transfer teknologi, training di bidang energi nuklir, dan sistem navigasi satelit BeiDou (China Daily, 2016).

China juga memberikan bantuan-bantuan kemanusiaan kepada negara-negara Arab yang sedang mengalami konflik. Misalnya, China mengirimkan 2000 pekerja medis ke Yaman untuk memperbaiki kondisi kesehatan masyarakat di negara tersebut; memberikan dana bantuan sebesar 7,62 juta USD kepada Palestina, dan 34,5 juta USD bantuan untuk membantu Suriah, Jordan, Lebanon, Libya, dan Yaman. Semua bantuan ini bermanfaat untuk memunculkan persepsi di tengah negara Arab bahwa China tidak memiliki 'ambisi kolonial' (Al Tamimi, 2017).

$$
\text { China juga menjadi }
$$
penyeimbang dalam konflik di kawasan, meskipun tetap berorientasi ekonomi dan perdagangan. Misalnya, dalam konflik Qatar versus Arab Saudi, Bahrain, dan Uni Emirat Arab, serta Mesir, China memberikan bantuan kepada Qatar dalam melepaskan diri dari tekanan ekonomi. Arab Saudi dan sekutunya telah memboikot tanah, udara, dan laut Qatar sehingga awalnya negara tersebut mengalami krisis pangan, pertumbuhan ekonomi berkurang drastis, dan cadangan devisa pun menipis. Namun, kerjasama dengan China menjadi solusi bagi Qatar. Ekspor Qatar ke China meningkat 60\% pasca embargo dan China menjadi sumber impor terbesar bagi Qatar. Akhirnya, pada 2018, Qatar sudah kembali stabil dengan cara membuka rute-rute perdagangan baru, bekerja sama dengan penyuplai baru, dan mengubah undang-undang investasi dan tenaga kerja (Chowdhury, 2018).

$$
\text { Menurut Alterman (2009) }
$$
pandangan negara-negara Timur Tengah kini mirip dengan bagaimana dulu mereka memandang AS yang membantu mereka keluar dari sisa-sisa dominasi Imperium Ottoman. Kini, ketika AS terlibat dalam berbagai konflik bersenjata dan penggulingan berbagai rezim dengan dalih menegakkan demokrasi, negaranegara Timur Tengah justru memandang AS tengah menjalankan ambisi imperialnya di kawasan, dan sebaliknya, menyambut baik China 
karena China menunjukkan ketidaktertarikan pada proses reformasi di negara-negara Arab. Dengan kata lain, China tidak ikut campur dalam politik domestik negara-negara Timur Tengah dan sikap ini sangat diapresiasi oleh mereka.

\section{Soft Power China Terhadap Iran}

Hubungan China dan Iran dapat dilacak sejak era Jalur Sutera kuno ribuan tahun yang lalu. Sebagai dua pusat peradaban dunia pada masa itu, China dan Iran (Persia) menjalin hubungan dagang secara intens dan tidak pernah terjadi perang di antara keduanya di masa lalu. Hal ini menjadi modalitas utama di antara kedua negara di era modern. Pada masa perang Iran-Irak (1980-1988), China lebih berpihak kepada Iran dengan pertimbangan bahwa karena Washington mendukung Baghdad, Teheran akan mendekat ke Moscow. Meskipun, pada saat itu China menjual senjata kepada kedua pihak, baik Iran maupun Iran. Selanjutnya, pada awal 1990-an, China menandatangani perjanjian dengan Iran untuk membantu Teheran mengembangkan energi nuklir (Mikhail, 2017).
Di era selanjutnya, seiring dengan semakin kuatnya dominasi AS, China dan Iran memiliki persamaan persepsi untuk melawan dominasi tersebut dan mempromosikan sistem internasional yang multipolar. Dalam hal ini, keduanya saling membutuhkan. Bagi China, Iran menjadi sumber peningkatan daya tawarnya di depan AS serta memberi peluang strategis bagi China untuk meningkatkan dominasinya di Timur Tengah (Escobar, 2018). Iran juga memiliki posisi penting dalam kesuksesan China untuk membangun kembali Jalur Sutra dalam proyek One Belt One Road Initiative. Secara umum, dengan posisi geostrategis yang dimiliki Iran, sumber daya migas yang sangat kaya, serta populasi yang cukup tinggi (lebih dari 78 juta), menjadikan Iran sebagai partner ekonomi dan politik yang sangat penting bagi China. Pada tahun 2017, ekspor minyak dan gas Iran mencapai 1 miliar barrel dan pengimpor terbesarnya adalah China. Pada pertengahan pertama tahun 2018, China tetap merupakan negara importir minyak terbesar Iran, meskipun secara akumulatif, negaranegara Eropa lebih banyak mengimpor 
dari Iran, sebagaimana terlihat dalam grafik berikut ini.

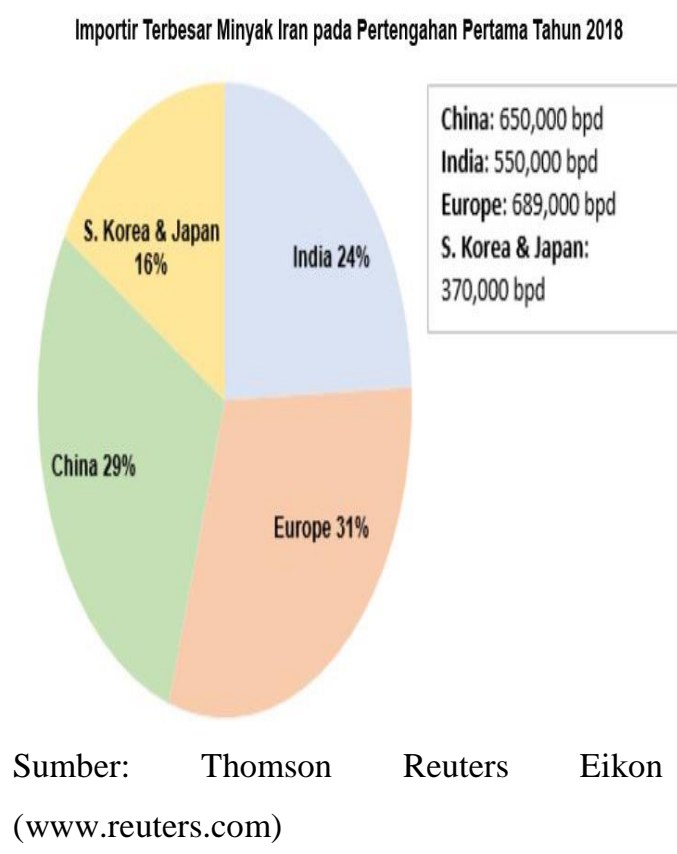

Hubungan antara kedua negara juga dijalin melalui berbagai institusi internasional seperti Shanghai Cooperation Organization (SCO) dan the Asian Infrastructure Investment Bank (AIIB). China juga membangun aliansi ekonomi yang berupaya melawan dominasi negara-negara Barat, yaitu BRICS (Brazil, Rusia, India, China, and South Africa). Dalam KTT BRICS bulan Juli 2018 di Johannesburg, disepakati deklarasi yang mengecam ekonomi yang bersifat unilateralisme dan menyerukan pentingnya ekonomi dunia yang terbuka (open world economy). Dalam pidatonya, Presiden $\mathrm{Xi}$ Jinping secara tersamar mengecam tindakan Trump dua bulan sebelumnya, yaitu secara sepihak keluar dari JCPOA. Xi menyeru agar semua pihak "mematuhi hukum internasional dan norma-norma dasar yang mengatur hubungan internasional dan menyelesaikan perselisihan melalui dialog dan membereskan perbedaan melalui konsultasi." Lebih jauh, Xi menyebut BRICS sedang membangun sebuah jenis baru hubungan internasional (Escobar, 2018).

BRICS dan Iran menjalin kerjasama yang signifikan dalam industri minyak, yaitu mencapai 53,78 juta ton, atau senilai 29 miliar USD per Maret 2018. India telah menjalin kesepakatan penyewaan pelabuhan Chabahar untuk dijadikan terminal kargo dengan tujuan menembus rute distribusi ke Afghanistan. Rusia dan Iran juga tengah membangun zona perdagangan bebas di bawah kerangka EEU (Eurasioan Economic Union). Bila EEU sudah berjalan, Iran akan memperoleh akses ke pasar yang lebih luas dan keluar dari jeratan sanksi ekonomi AS (The Brics Post, 2018)

Dalam beberapa kajian yang dilakukan oleh akademisi Iran, disimpulkan bahwa nilai strategis Tehran di mata Beijing adalah posisi 
geopolitik, dimana selama Iran terus menjadi sumber distraksi utama bagi AS, posisi China akan lebih aman. Beijing memandang Washington sebagai ancaman yang mampu menghentikan suplai energi dari Timur Tengah seandainya terjadi konflik militer di antara kedua pihak. Dengan demikian, kerjasama yang kuat di bidang ekonomi, militer, dan budaya dengan Iran memiliki nilai penting bagi China dalam upayanya mengimbangi kekuatan AS di Timur Tengah (Talebi, 2017, Amiri dan Khanar, 2017).

Dampak relasi China-Iran adalah melunaknya sikap AS terhadap China, sekaligus di saat yang sama memberikan ancaman. Untuk menyukseskan embargo yang diterapkan sepihak oleh AS terhadap Iran, AS membutuhkan keikutsertaan semua negara, terutama negara yang memiliki nilai perdagangan tinggi seperti China. Di bawah tekanan AS, hampir semua partner dagang Iran telah menurunkan volume dagangnya sejak 2009. Namun, perusahaanperusahaan China justru memanfaatkan kekosongan Eropa dan Jepang di Iran untuk memperluas kerjasama ekonominya, mulai dari migas hingga proyek infrastruktur, seperti pembangunan sistem kereta api bawah tanah (metro) di Teheran dan pembangunan jalan. Dalam menghadapi sikap China ini, AS berusaha strategi 'guarded engagement', yaitu di satu sisi mengakomodasi kepentingan dan keinginan China, tetapi di sisi lain juga memberikan tekanan kepada Beijing, antara lain melalui sanksi ekonomi (Izadi dan Khodaee, 2017).

Sikap China yang konsisten menolak tekanan AS dalam perspektif Iran dipandang sebagai bentuk kesetiaan. Amiri dan Khanar (2017) dalam penelitiannya, di antara faktor penting yang mendorong kerjasama yang kuat antara China dan Iran adalah faktor kesetiaan China selama Iran diembargo AS. Pada dasarnya, kebijakan luar negeri Iran adalah pragmatik dan realistis (Amiri dan Khanar, 2017; Talebi, 2017). Dalam perspektif ini, sikap konsisten dan setia China dapat dipandang sebagai bentuk soft power untuk menarik Iran agar menjalin kerjasama yang lebih intens.

Seiring dengan itu, China juga memiliki posisi yang sama dengan Iran dalam problem meningkatnya radikalisme di kawasan. Baik China maupun Iran sama-sama terancam 
oleh kelompok-kelompok teroris yang berideologi Wahhabisme, seperti Al Qaida dan ISIS. Pada tahun 2014, pemimpin ISIS, Abu Bakr AlBaghdadi telah mengeluarkan ancaman akan membalas dendam kepada negara-negara yang dianggapnya telah melanggar hak kaum muslimin, dan China masuk ke dalam daftar negara yang diancamnya. Al Baghdadi bahkan menyerukan agar kaum Muslim Uighur bergabung dalam 'perang suci' bersama ISIS. Data dari Kementerian Pertahanan Irak, dan sumber di Indonesia menunjukkan ditemukannya orangorang Uighur menjadi anggota ISIS (Chaziza, 2016). Milisi ISIS asal Uighur juga ikut bertempur di Suriah. Sementara itu, Iran juga berkali-kali menjadi korban aksi bom bunuh diri dari anggota ISIS atau kelompok radikal sejenis. Dalam konflik Suriah, dimana Iran membantu pemerintah Assad memerangi berbagai milisi teror (ISIS maupun Al Qaida dan afiliasinya), China pun memberikan dukungan diplomatik, antara lain memveto resolusi Dewan Keamanan Barat yang menghendaki serangan militer terhadap Suriah.

Militer China dan Iran telah melakukan kerjasama militer, khususnya dalam menangani terorisme. Pada September 2018, Menteri Pertahanan Iran berkunjung ke China untuk bertemu dengan Menteri Pertahanan China dan kedua pejabat menyatakan bahwa kedua negara memiliki kepentingan yang sama serta ancaman bersama, yaitu terorisme. Sebelumnya pada November 2016, pejabat militer kedua negara telah menandatangani perjanjian di Teheran untuk meningkatkan kerjasama pertahanan militer dan memerangi terorisme (Press TV, 2018). Pada 2014, Meng Jianzhu, pejabat pemimpin upaya antiteror di China, telah mengunjungi Iran untuk mencari dukungan dalam menjaga stabilitas di Xinjiang yang terancam oleh aksi-aksi terorisme yang telah menewaskan ratusan orang (Reuters, 2014).

Amiri dan Khanar (2017) menyimpulkan ada 6 faktor yang mendorong intensnya kerjama bilateral China-Iran, yaitu, pertama seperti sudah dikutip sebelumnya, kesetiaan China terhadap Iran selama masa embargo AS; rendahnya tingkat ketidakpercayaan Iran terhadap Barat, isi perjanjian ekonomi Iran-Cina [yang dianggap menguntungkan], posisi geopolitik dan geostrategis Iran bagi 
China, adanya musuh bersama, yaitu kelompok-kelompok fundamentalis, dan kesamaan posisi politik kedua pihak yang menentang sistem tata dunia yang didominasi oleh unilateralisme AS. Nilai kesetiaan yang dipegang China ini tersirat dalam tulisan Presiden $\mathrm{Xi}$ Jinping yang dimuat di media massa Iran, yang menceritakan betapa persahabatan China-Iran sudah berusia ribuan tahun, antara lain dalam kalimat, "Indeed, the thousand-mile-long land and maritime silk roads made it possible for two ancient civilizations and peoples to embrace and befriend each other. As Saadi wrote, those that are far away and are of times long past deserve to be cherished more" (www.fmprc.gov.cn).

Keenam faktor tersebut, empat di antaranya sangat terkait dengan nilai: kesetiaan, penolakan terhadap fundamentalisme, dan perlawanan terhadap sikap unilateral AS. Inilah bentuk soft power yang khas dari China yang diimplementasikan terhadap Iran dan disambut dengan sangat positif oleh Iran. Selain itu, inisiatif One Belt One Road dari China memiliki kesamaan latar belakang budaya dengan Iran sebagai bekas dua imperium besar, China dan Persia. Iran memandang Jalur Sutra era baru ini membawa simbol kebanggaan masa lalu dan hal ini menjadi aset diplomatik yang besar bagi China untuk mempengaruhi kawasan Timur Tengah, khususnya Iran (Talebi, 2017).

Dengan demikian, dari enam elemen yang menjadi sumber bagi soft power China, sebagaimana dipaparkan oleh Osman (2017), yang lebih banyak terimplementasi di Iran adalah kesuksesan ekonomi dan pembangunan a la China (sehingga memberi kepercayaan kepada Iran untuk memberikan proyek-proyek migas dan infrastrukturnya kepada China) serta relasi diplomatik yang canggih. Dalam hal relasi diplomatik ini, yang dilakukan China adalah menunjukkan kesamaan nilai mendasar yang dipegang kesetiaan kepada Iran di masa-masa sulit akibat embargo AS, kesamaan pandangan terhadap bahaya radikalisme dan terorisme, serta kesamaan persepsi di hadapan dominasi AS (sama-sama menolak dominasi AS). Tentu saja, implementasi soft power ini merupakan upaya untuk mencapai kepentingan China, yaitu mengamankan suplai energi, 
mempertahankan

keamanan

wilayahnya

sendiri,

serta

menyeimbangkan kekuatan di hadapan

AS.

\section{Kesimpulan}

China memiliki kemampuan unik dalam menjalin hubungan ekonomi, politik, dan budaya dengan negara-negara di Timur Tengah. Di tengah berbagai konflik dan perseteruan di kawasan tersebut, China mampu memposisikan diri sebagai teman bagi semua pihak sehingga kepentingan ekonomi China dapat diraih di negara-negara yang saling bermusuhan sekalipun. Misalnya, nilai perdagangan China meningkat pesat di Qatar pasca embargo Arab Saudi; namun di saat yang sama China juga menjalin hubungan ekonomi yang erat dengan Arab Saudi; atau, nilai perdagangan China dengan Israel cukup signifikan, sementara China tetap menjadi sekutu terdekat Iran. Strategi politik yang digunakan China dalam menjalin hubungan dengan negara-negara Timur Tengah adalah soft power, yaitu penggunaan institusi, nilai, budaya, dan kebijakan untuk menarik pihak lain agar pihak lain tersebut mau melakukan apa yang dikehendaki China.
Khusus untuk kasus ChinaIran, China mendapatkan posisi penting dalam pembangunan ekonomi di Iran berkat beberapa dimensi soft power, yaitu pertama, kesuksesan ekonomi dan pembangunan yang diraih China memberikan kepercayaan kepada pihak Iran untuk menyerahkan berbagai proyek penting di bidang minyak, gas, dan infrastruktur kepada China; dan kedua, relasi diplomatik yang mumpuni. Dalam bidang diplomatik ini, China mengedepankan kesamaan nilai (values)-nya dengan Iran, yaitu nilai persahabatan dan kesetiaan.

\section{Daftar Referensi}

Amiri, R.I. dan Khanar, M.S. 2017. Bar Resiye Elal-e Zamineh haye Gostaresh-e Ravabete Iran va Chin dar Asr-e Pasa Barjam [Analisis Sebab dan Bidang Perluasan Hubungan Iran-China Pasca JCPOA]. Siyasat va Ravabete Bainal Melali (Journal of Politics and International Relations. (1) $\quad 1$. http://jpir.journals.umz.ac.ir/arti cle_1606.html

Abrams, E. 2018. What's Behind Israel's Growing Ties With China? 
https://www.cfr.org/expert-

brief/whats-behind-israels-

growing-ties-china [diakses 15

November 2018]

Albert, E. 2018,. China's Big Bet on Soft Power. Dalam: https://www.cfr.org/backgrounde r/chinas-big-bet-soft-power [diakses 15 November 2018]

Al Tamimi, J. 2017. China uses soft power to woo Arab world. Dalam https://gulfnews.com/world/men a/china-uses-soft-power-to-wooarab-world-1.2105970 [diakses 15 November 2018]

Alterman, J.B. China's Soft Power in The Middle East. Dalam McGiffert, C. (ed). 2009. Chinese Soft Power and Its Implication for The United States. Washington: CSIS.

Chaziza, M. 2016. China's Middle East Policy: The ISIS Factor. Middle East Policy Council, Vol. XXIII Spring. Dalam https://www.mepc.org/journal/ch inas-middle-east-policy-isis- factor. [diakses 15 November 2018]

Chen, Q. (1993). New Approaches in China's Foreign Policy: The Post-Cold War Era. Asian Survey, [online] 33 (3), 237-251. URL:

http://www.jstor.org/stable/2645

249 [Diakses 5 Oktober 2018].

China Daily. 2016. President Xi's Speech at Arab League Headquarters: Full Text. Dalam http://www.chinadaily.com.cn/w orld/2016xivisitmiddleeast/201601/22/content_23191229.htm [diakses 22 November 2018]

Chowdhury, D.R. 2018. China A Pillar Of Strength In Qatar's Fightback Against Arab Blockade. Dalam: https://www.scmp.com/weekasia/geopolitics/article/2149915/ china-pillar-strength-qatarsfightback-against-arab-blockade. [diakses 15 November 2018]

Donati, J. 2018. U.S. Signals It Could Sanction China Over Iran Oil Imports. Dalam: https://www.wsj.com/articles/po 
mpeo-announces-new-action-

group-to-target-iran-1534445395

[diakses 20 November 2018]

Escobar, P. 2018. How BRICS Plus clashes with the US economic war on Iran. http://www.atimes.com/article/h ow-brics-plus-clashes-with-theus-economic-war-on-iran/ [diakses 22 November 2018]

Financial Tribune. 2018. China to Be Major Beneficiary of US' Iran Nuclear Deal Pullout. Dalam: https://financialtribune.com/artic les/economy-business-andmarkets/86191/china-to-bemajor-beneficiary-of-us-irannuclear-deal [diakses 20 November 2018]

FMPRC (Ministry of Foreign Affairs of People's Republic of China). Full text of Chinese president's signed article on Iranian newspaper. Dalam https://www.fmprc.gov.cn/mfa_e ng/wjdt_665385/zyjh_665391/t1 334040.shtml [diakses 25 November 2018]
Izadi, F. Dan Khodaee, E. 2017. The Iran Factor in U.S.-China Relations: Guarded Engagement vs. Soft Balancing. China Quarterly of International Strategic Studies, Vol. 3, No. 2, 299-323. DOI: 10.1142/S2377740017500105

McGiffert, C. (ed). 2009. Chinese Soft Power and Its Implication for The United States. Washington: CSIS.

Mikhail, B.S. 2017. China's Relations with Arabia and the Gulf 19491999 (Book Review). Dalam: https://www.mepc.org/chinasrelations-arabia-and-gulf-19491999 [diakses 22 November 2018]

Nye, J.S. Jr. 2004. Soft power: the means to success in world politics. New York: Public Affairs

Osman, R. 2017. China's soft power: an assessment of positive image building in the Middle East. (Tesis Master di Leiden University) 
Press TV. 2018. Iran, China discuss enhanced defense cooperation, anti-terror fight. Dalam https://www.presstv.com/Detail/ 2018/09/07/573442/Hatami-

Wei-Fenghe-Iran-Chinaterrorism-defense [diakses 15 November 2018]

Reuters, 2014. China's top domestic security chief visits Iran to push for anti-terror cooperation. Dalam:

https://www.reuters.com/article/ us-china-iran/chinas-topdomestic-security-chief-visitsiran-to-push-for-anti-terrorcooperationidUSKCNOJ204W20141118 [diakses 20 November 2018]

Sputnik. 2018. US Threatens China With Sanctions for Iranian Oil Imports. Dalam: https://sputniknews.com/us/2018 08171067277290-us-chinasanctions-threat/ [diakses 20 November 2018]

Talebi, S. 2017. Iran-China Relations: An Iranian Perspective. Dalam https://www.twai.it/magazines/ir an-china-relations-an-iranian- perspective/ [diakses 30 Oktober 2018]

The Brics Post. 2018. Iran does brisk business with BRICS. Dalam http://thebricspost.com/irandoes-brisk-business-withbrics/\#.W_jLwegzY2w [diakses 15 November 2018]

USA Today. 2017. Dalam: https://www.usatoday.com/tory/mone y/2017/03/17/china-saudi-arabia-sign65-billion-cooperationdeals/99295228/[diakses 15 November 2018]

Zhou, L. 2018. China pledges US\$23 billion in loans and aid to Arab states as it boosts ties in Middle East. Dalam: https://www.scmp.com/news/chi na/diplomacydefence/article/2154642/chinapledges-us23-million-loans-andaid-arab-states-it [diakses 20 November 2018] 